\title{
The Effect of Salt and pH on the Phase Transition Behaviors of $\mathrm{pH}$ and Temperature- Responsive Poly( $N, N$-diethylacrylamide-co-methylacrylic acid)
}

\author{
Tonghuan Liu, Jian Fang, Yaping Zhang, and Zhengzhi Zeng* \\ College of Chemistry and Chemical Engineering, Lanzhou University, Lanzhou, P.R. China
}

Received December 30, 2007; Revised June 12, 2008; Accepted June 25, 2008

\begin{abstract}
A series of $\mathrm{pH}$ and temperature-responsive ( $N, N$-diethylacrylamide-co-methylacrylic acid) copolymers were synthesized by radical copolymerization and characterized by elemental analysis, Fourier-transform infrared (FT-IR), nuclear magnetic resonance (NMR) ${ }^{1} \mathrm{H},{ }^{13} \mathrm{C}$ and LLS. The effects of salt and $\mathrm{pH}$ on the phase transition behaviors of the copolymers were investigated by UV. With increasing $\mathrm{NaCl}$ concentration, significant salt effects on their phase transition behaviors were observed. UV spectroscopic studies showed that the phase transition became faster with increasing $\mathrm{NaCl}$ concentration. In addition, the phase transition behaviors of copolymers were sensitive to $\mathrm{pH}$. The $\mathrm{pH}$ and temperature sensitivity of these copolymers would make an interesting drug delivery system.

Keywords: poly( $N, N$-diethylacrylamide-co-methylacrylic acid), salt effects $\mathrm{pH}$ and temperature sensitivity, phase transition, UV spectroscopic.
\end{abstract}

\section{Introduction}

The unique and novel properties of intelligent polymeric materials, which exhibit large property changes in response to small changes in external stimulate such as temperature, ${ }^{1,2}$ $\mathrm{pH},{ }^{3,4}$ electric fields, ${ }^{5,6}$ chemicals, ${ }^{7,8}$ offer an unlimited amount of potential applications in various fields, such as industry, the environment and the biomedical field. ${ }^{9-12}$

Poly( $N$-isopropylacrylamide), PNIPA, ${ }^{13-18}$ is by far the beststudied and most prominent temperature responsive polymer. PNIPA exhibits a well defined lower critical solution temperature (LCST) in water at $32{ }^{\circ} \mathrm{C}$ around, below LCST the PNIPA are water soluble and above which they become water insoluble. It is known that the phase transition is the results of a delicate balance between the hydrophobic interactions and hydrogen bonding. Besides PNIPA, several other $N$-substitute poly(acrylamide), such as poly $(N, N$-diethylacrylamide) (PDEA), $N$-ethylacrylamide, $N$-cyclopropylacrylamide, also exhibit the phase transition behavior.

Recently, there has been considerable interest in the use of materials that respond to two stimulus, either mutually or independently in specific environments with particular emphasis on temperature and $\mathrm{pH}$ responsive polymers, ${ }^{19,20}$ because some disease states manifest themselves by a change in temperature and/or $\mathrm{pH}^{21,22}$ Especially as drug carriers have attracted tremendous attentions over the last decade.

*Corresponding Author. E-mail: zengzhzh@yahoo.com.cn
At present, a few studies have been carried out to investigate the salt and $\mathrm{pH}$ effects on their phase transition behaviors. ${ }^{23-25}$ It would be fundamentally important to investigate such effects as blood and other body fluids are not salt free, and variations on the variety and concentration of salts as well as $\mathrm{pH}$ in human body exist. In this paper, a series of temperature- and $\mathrm{pH}$-responsive $N, N$-diethylacrylamide (DEA)-co-methylacrylic acid (MAA) copolymers were synthesized by free radical copolymerization techniques and determined their temperature and $\mathrm{pH}$ sensitive properties by transmittance measurements. The aim of the present study is to design a copolymer, which is temperature and $\mathrm{pH}$-responsive. The study focuses on the phase transition of copolymers of DEA-co-MAA over a wide range of salt concentrations. The effect of the MAA content and $\mathrm{pH}$ values on the LCST of the copolymers was also investigated in this paper.

\section{Experimental}

Materials. Acryloyl chloride (99\%), diethylamine (99\%), 2,2-azobisisobutyronitrile (AIBN, 98\%) were used as received from Chemical reagent, shanghai. MAA $(96 \%$, Chemical reagent, tianjin) was distilled under reduced pressure before polymerization and other chemicals were of analytical reagent grade used without further purification. AIBN was recrystallized from $95 \%$ ethanol. All aqueous solutions were prepared by deionized water. 


\section{Synthesis.}

$\boldsymbol{N}, \boldsymbol{N}$-Diethylacrylamide: DEA was synthesized according to procedures reported by Idziak I et al.. ${ }^{26}$ Briefly, a solution of acryloyl chloride $(46.7 \mathrm{~mL})$ in $30 \mathrm{~mL}$ dichloromethane was added slowly into the mixture of diethylamine $(208 \mathrm{~mL})$ and dichloromethane $(450 \mathrm{~mL})$. The reaction temperature was kept $0{ }^{\circ} \mathrm{C}$ under nitrogen and stirring for $10 \mathrm{~h}$. The salt precipitated was removed by filtration. The filtrate was abstersion by distilled water for many times, and then the filtrate was stripped off the solvent by rotary evaporator. The crude product was then distilled in the presence of hydroquinone under vacuum. DEA: bp $89{ }^{\circ} \mathrm{C}(9.4 \mathrm{mmHg})$. $300 \mathrm{MHz}^{1} \mathrm{H} \mathrm{NMR}\left(\mathrm{CDCl}_{3}, \delta \mathrm{ppm}\right) ; 1.11(\mathrm{tt}, 6 \mathrm{H}, \mathrm{J}=6.3 \mathrm{~Hz}$, $\left.-\mathrm{CH}_{3}\right), 3.36\left(\mathrm{~m}, 4 \mathrm{H}, \mathrm{J}=7.8 \mathrm{~Hz},-\mathrm{CH}_{2}-\right), 5.62(\mathrm{dd}, 1 \mathrm{H}, \mathrm{J}=9.9$ and $\left.1.8 \mathrm{~Hz}, \mathrm{CH}_{2}=\right), 6.29\left(\mathrm{dd}, 1 \mathrm{H}, \mathrm{J}=17.1\right.$ and $\left.1.8 \mathrm{~Hz}, \mathrm{CH}_{2}=\right)$, $6.51(\mathrm{dd}, 1 \mathrm{H}, \mathrm{CH}=, \mathrm{J}=17.1$ and $9.9 \mathrm{~Hz}) .300 \mathrm{MHz}{ }^{13} \mathrm{C} \mathrm{NMR}$ $\left(\mathrm{CDCl}_{3} \delta \mathrm{ppm}\right): 12.95$ and $14.72\left(-\mathrm{CH}_{3}\right) ; 40.66$ and 42.05 $\left(-\mathrm{CH}_{2}-\right) ; 127.76\left(\mathrm{CH}_{2}=\right) ; 127.40(\mathrm{CH}=) ; 168.44(>\mathrm{C}=\mathrm{O})$.

$\operatorname{Poly}(N, N$-diethylacrylamide-co-methylacrylic Acid) (P(DEA-co-MAA)). Temperature- and pH-responsive $\mathrm{P}$ (DEA-co-MAA) consisting of DEA and MAA with various molar ratios was synthesized by radical copolymerization with AIBN as an initiator. The monomers of DEA and MAA were dissolved in methanol and the solution was heated at $62{ }^{\circ} \mathrm{C}$ for $10 \mathrm{~h}$ in a nitrogen atmosphere. The product was solved in acetone and precipitated in hexane. After filtration, the copolymer was dried in vacuum chamber at room temperature for 2 days. In this report, the copolymers with different molar ratios of DEA to MAA 78/22, 82/18, $86 / 14$ and $89 / 11$ ) were synthesized and represented by $1^{\#}$, $2^{\#}, 3^{\#}, 4^{\#}$ respectively.

Copolymers Characterization. The DEA content in the copolymers was determined by element analysis using an Elemental vario-EL element analyzer. Molecular weights were measured by a Brookhaven BI-200SM gonimeter laser light scattering (LLS) instrument using methanol as solvent. IR spectra were recorded on a Nicolet Avatar 360 FT-IR instrument using $\mathrm{KBr}$ discs in the $400-4000 \mathrm{~cm}^{-1}$ region. ${ }^{1} \mathrm{H}$ $\mathrm{NMR}$ and ${ }^{13} \mathrm{C}$ NMR spectra were measured on a Varian Mercury-300 BB NMR spectrometer.

The Determination of LCST of Copolymers in Different NaCl Solutions. Optical transmittances of aqueous copolymers solutions $1^{\#}(\mathrm{pH}=4.06-4.23), 2^{\#}(\mathrm{pH}=4.47-4.62), 3^{\#}(\mathrm{pH}=$ $5.15-5.25), 4^{\#}(\mathrm{pH}=5.49-5.54)$ with different $\mathrm{NaCl}$ concentrations and $0.2 \mathrm{wt} \%$ copolymer concentration at various temperatures were measured at $500 \mathrm{~nm}$ with a UV-Vis spectrometer (Agilent 8453E). At the temperatures near the LCST, the temperature-rising interval was set at $0.5-0.8^{\circ} \mathrm{C}$. The sample cells were equilibrated at a given temperature for $30 \mathrm{~min}$ with the whole period being monitored by timecourse UV spectroscopy; the end point transmittances were recorded. The determinations were carried out continuously. The LCST values of copolymer solutions were determined at the temperatures showing an optical transmittance of 50\%.

LCST of Copolymers in Different pH Solution. The LCST of copolymers in different $\mathrm{pH}$ solutions were conducted in the same way as described in the section of "The determination of LCST of copolymers in different $\mathrm{NaCl}$ solutions". The $\mathrm{pH}$ solutions were adjusted by appropriate $\mathrm{HCl}$ or $\mathrm{NaOH}$ solutions. All the solutions contained the same content of $\mathrm{NaCl}(1.0 \mathrm{~g} / \mathrm{L})$ to keep a constant ionic strength.

\section{Results and Discussion}

Copolymers Characterization. According to the results of composition determination, the structural unit of the copolymer is shown by the scheme in Figure 1, where $\mathrm{x}$ is the mol ratio of MAA/DEA in the copolymer.

The compositions and molecular weights of copolymers are shown in Table I. Fujishige et al. ${ }^{27}$ found that LCST of PNIPAM is independent of molecular weight. In our experiment they are in the same quantitative indicator $\left(10^{-5}\right)$. The

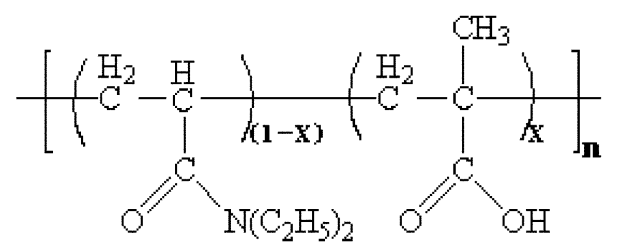

Figure 1. Scheme of the PDEA-co-MAA copolymer.

Table I. Composition and Molecular Weights of Copolymers

\begin{tabular}{ccc}
\hline Sample & DEA/MAA Molar Ratio Copolymer & $M w(\mathrm{~g} / \mathrm{mol})$ \\
\hline $1^{\#}$ & $77.57 / 22.43$ & 47,590 \\
$2^{\#}$ & $82.02 / 17.98$ & 80,058 \\
$3^{\#}$ & $85.87 / 14.13$ & 50,035 \\
$4^{\#}$ & $89.08 / 10.92$ & 36,776 \\
\hline
\end{tabular}

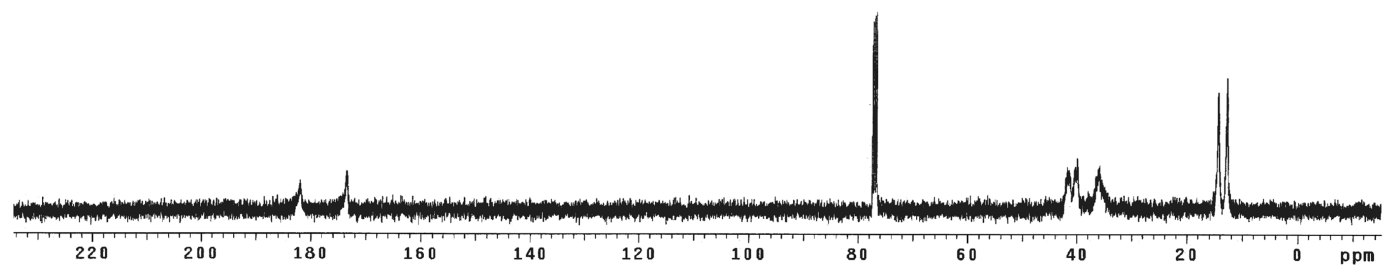

Figure 2. ${ }^{13} \mathrm{C}$ NMR spectrum of PDEA-co-MAA. 
result indicated that the LCST of different copolymers were affected in the same way by $\mathrm{NaCl}$ solutions or $\mathrm{pH}$. So the difference of the $M w$ of copolymers could be neglected in our experiment. The IR spectrum of monomer are observed at $1607 \mathrm{~cm}^{-1}$ for the $\mathrm{C}=\mathrm{C}$, at $1647 \mathrm{~cm}^{-1}$ for the $\mathrm{C}=\mathrm{O}$ (Amide I), while MAA groups are reported to appear at $1706 \mathrm{~cm}^{-1}$ for the $\mathrm{C}=\mathrm{O}$ of carboxylic group. In this work, characteristic peaks for the copolymers are observed at $1722 \mathrm{~cm}^{-1}$ for the $\mathrm{C}=\mathrm{O}$, at $1635 \mathrm{~cm}^{-1}$ for the $\mathrm{C}=\mathrm{O}$ (Amide I). While the 1607 $\mathrm{cm}^{-1}(\mathrm{C}=\mathrm{C})$ disappeared in the spectra of copolymers indicating that the polymerization reaction has taken place.

Figure 2 shows the ${ }^{13} \mathrm{C}$ NMR spectrum of copolymer in $\mathrm{CDCl}_{3}$. The signals at $12.795,14.311,35.812-41.756$, and 76.684-77.328 ppm are corresponded to the aliphatic carbons, while the peaks at 173.554 and $181.988 \mathrm{ppm}$ are ascribed to the carbons of carbonyl group and carboxylic group, respectively.

The Salt Effect on the LCST of Copolymers. In an electrolyte solution, the phase transition of copolymers is determined by various coexistent intra- and intermolecular forces such as Van der Waals force, hydrogen bonding, hydropho- bic interaction and electrostatic force. It has been reported that some salts increase the LCST (in which case it is called 'salting-in effect'), whereas other salts decrease the LCST (in which case it is called 'salting out' effect). ${ }^{28}$ The phase transition of the copolymers in presence of $\mathrm{NaCl}$ a fairly weak salting out agent was studied.

Figure 3 shows the LCST curves of copolymers by monitoring the transmittance change of $0.20 \%$ aqueous solutions of $1^{\#}-4^{\#}$ with the increasing of $\mathrm{NaCl}$ concentrations.

With the increase of $\mathrm{NaCl}$ concentration from 0.0 to $10.0 \mathrm{~g} / \mathrm{L}$, significant decreases in LCST of all the copolymers are observed, and the transition of the transmittance curve becomes sharper. Two factors may affect the self-associations of the hydrophilic and amphiphilic polymers. On one hand, the addition of $\mathrm{NaCl}$ increases the hydrogen bonding among water molecules and decreases that among water and hydrophilic chains. Subsequently the hydrogen bonding among the hydrophilic chains becomes dominant, which results in a stronger tendency for the copolymers to associate and decrease their $\operatorname{LCST}^{29,30}$ On the other hand, the presence of $\mathrm{NaCl}$ will undoubtedly increase the polarity of
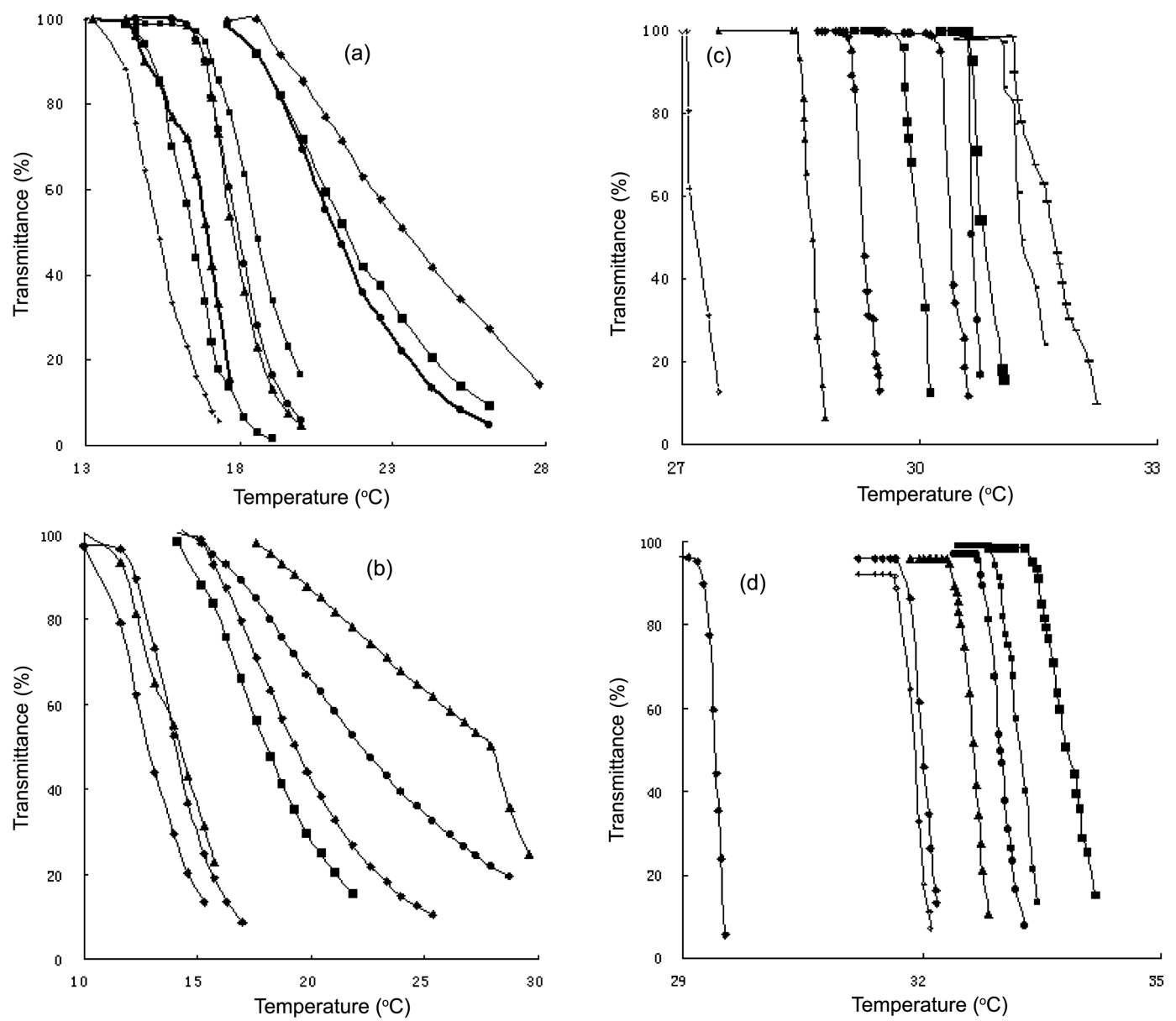

Figure 3. Salt effect on the LCST of copolymers by monitor the transmittance change of $0.20 \mathrm{wt} \%$ aqueous copolymers solutions with different $\mathrm{NaCl}$ concentrations as a function of temperature. From left to right: $\mathrm{NaCl}(\mathrm{g} / \mathrm{L}) 10,5.0,2.0,1.0,0.5,0.2,0.1,0.05$ and 0.0 , respectively. (a): $1^{\#}$ (c): $3^{\#}$ (d): $4^{\#}$; From left to right: $\mathrm{NaCl}$ (g/L) 10, 5.0, 2.0, 1.0, 0.5, 0.1 and 0.05 for (b): $2^{\#}$. 
aqueous media thus enhance the hydrophobic-hydrophobic interactions. The stronger hydrophobic-hydrophobic interaction the stronger tendency for the copolymers to self aggregate, so the copolymer chain in the salt solution is less extended; a feature that will result in a less solubility of the polymer in water hence decreases its $\operatorname{LCST}^{31}$ and a sharper phase transition.

Figure 3 also indicates that the transition curves of $1^{\#}$ and $2^{\#}$ were very much broader than $3^{\#}$ and $4^{\#}$. As the spectrophotometer can only detect particles larger than the scanning wavelength, ${ }^{26}$ the difference in the transition curves indicates that there are differences in sizes of the collapsed aggregates for the two systems. ${ }^{32}$ For the copolymers incorporation of a small amount of MAA increases the hydrophilicity and thus affects the LCST of the copolymers. It is reasonable to suggest that the electrostatic repulsion among the ionized carboxylic acid groups could have prevent the copolymer chains to aggregate further to bigger particle size. ${ }^{32}$ As the $1 \#$ and $2 \#$ molecular weights of MAA block is higher than the $3^{\#}$ and $4^{\#}$. So the transition curves of $1^{\#}$ and $2^{\#}$ were much broader.

Figure 4 shows the influence of $\mathrm{NaCl}$ concentration on the LCST of copolymer solution. The LCST of copolymers solutions decrease with the increasing of $\mathrm{NaCl}$ concentrations. The influence can be disparted into two parts; when $\mathrm{NaCl}$ concentrations are below $1.0 \mathrm{~g} / \mathrm{L}$, the curve of the change LCST with $\mathrm{NaCl}$ concentration is sharp, while $\mathrm{NaCl}$ concentrations above $1.0 \mathrm{~g} / \mathrm{L}$, the influence become smaller. The effect can be regarded as the charge repulsion among the partially deionized MAA segments, which can be screened by addition of electrolytes, to yield a more compacted conformation. When the concentrations of $\mathrm{NaCl}$ arrive at a certain concentration, the screening effect increase is smaller by adding additional $\mathrm{NaCl}$, the influence on LCST become gentle.

The MAA Content Effect on the LCST of Copolymers. The effect of MAA content on the LCST is presented in
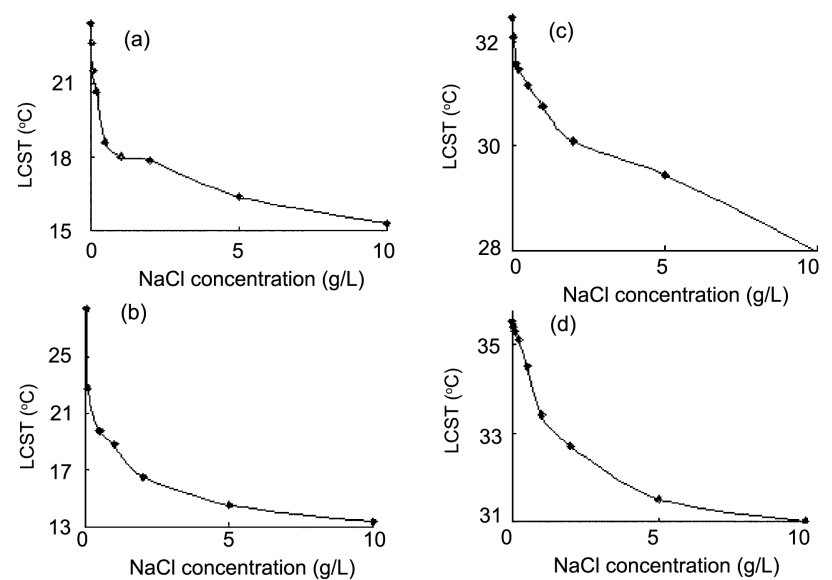

Figure 4. Salt effect on the LCST of copolymer. (a): $1^{\#},(b): 2^{\#}$, (c): $3^{\#},(d): 4^{\#}$.

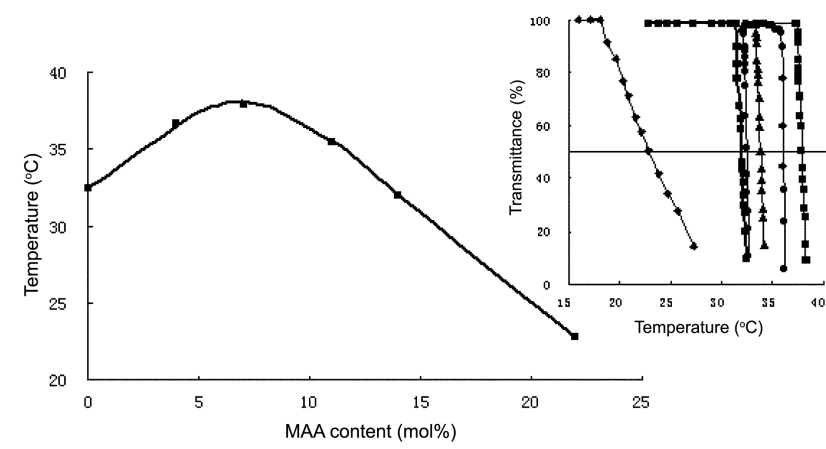

Figure 5. Effect of MAA content on the LCST values of copolymer aqueous solutions at $2.0 \mathrm{~g} / \mathrm{L}$. Insets: MAA content on the LCST of copolymer by monitoring the transmittance change of aqueous copolymer solutions with different MAA content as a function of temperature. From left to right: MAA content (mol\%) of $22,14,0,11,4$ and 7 , respectively.

Figure 5. In Figure 5 six (MAA content (mol\%) of 22, 14, $11,7,4$ and 0 , respectively. The $M w(\mathrm{~g} / \mathrm{mol})$ of them is 47,950 , $50,035,36,776,45,682,40,852$ and 49,847) copolymers were invested. The LCST values were found to increase slightly initially with increasing MAA content; further increase MAA content induced the LCST to decrease. This finding is consistent with the result previously reported by L.-H. Gan et $a l .{ }^{32}$ It is reasoned that by incorporating a small amount of MAA, the hydrophilicity of the copolymer increases, through hydrogen bonding with water, thus causing the LCST to increase. ${ }^{32}$ As the MAA content increases, the hydrogen bonding between two carboxylic acid groups, and between carboxylic acid and amide groups (intra-molecular and inter-molecular) ${ }^{33}$ also increases, causing the polymer chain to collapse at a lower temperature.

The pH Effect on the LCST of $\left(1^{\#}-4^{\#}\right)$ Copolymers. The $\mathrm{pH}$ effects on the phase transition behaviors of copolymers $\left(1^{\#}-4^{\#}\right)$ were investigated. All samples contained $1.0 \mathrm{~g} / \mathrm{L} \mathrm{NaCl}$ to keep a constant ionic strength. Figure 6 shows the LCST curves of $\left(1^{\#}-4^{\#}\right)$ in different $\mathrm{pH}$.

The $\mathrm{pH}$ shows a strong effect on the LCST of copolymers: The results indicate that the $\mathrm{pH}$ effect on the LCST of copolymer solution which is shown in Figure 6. It can be seen in Figure 6, with the increase of $\mathrm{pH}$ the LCST increases. The change of LCST is exiguity when the $\mathrm{pH}$ is lower than 4.0 , but it becomes sharp when $\mathrm{pH}$ is between 4.0 and 8.0. Then the plateau values are obtained after $\mathrm{pH}=8.0$. The slopes of these curves in the transition regions are lowered with decreasing $\mathrm{pH}$, partially because electrostatic repulsion between negative charges on ionized $(-\mathrm{COOH})$ units prevents aggregation of the globules formed from copolymers chains. The ionization states of MAA units are dependent on $\mathrm{pH}$, and the properties of neutral and ionized forms are quite different. That is to say, MAA units exist in an ionized form $\left(-\mathrm{COO}^{-}\right)$when the $\mathrm{pH}$ arrive at a certain value and repulsive interactions occur between them, whereas MAA 

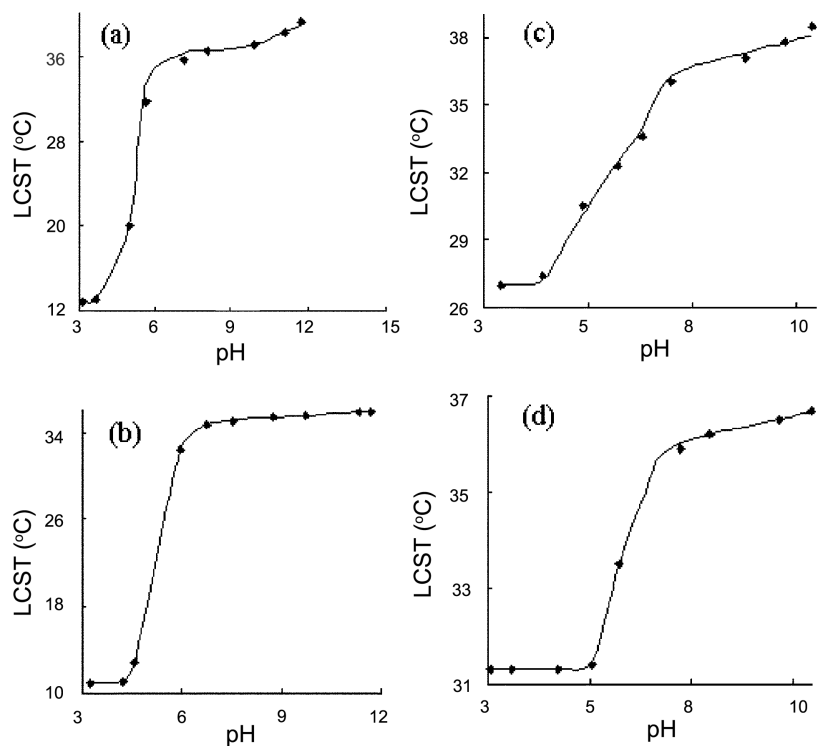

Figure 6. pH effect on LCST of $0.20 \mathrm{wt} \%$ copolymers in different $\mathrm{pH}$ solutions as a function of temperature. All the solutions contained $1.0 \mathrm{~g} / \mathrm{L} \mathrm{NaCl}$. (a): $1^{\#}$, (b): $2^{\#}$, (c): $3^{\#}$, (d): $4^{\#}$.

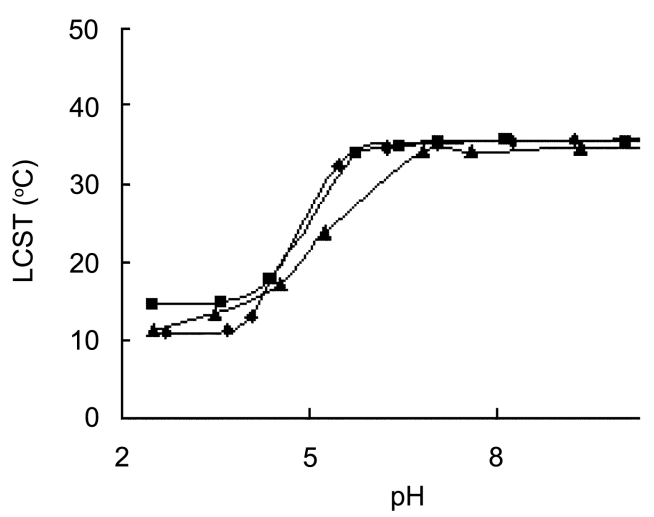

Figure 7. pH Effect on LCST of $0.20 \mathrm{wt} \%$ copolymer $\left(2^{\#}\right)$ in different salt solutions as a function of temperature. $-0.5 \mathrm{~g} / \mathrm{L}$ $\mathrm{NaCl},-1.0 \mathrm{~g} / \mathrm{L} \mathrm{NaCl}, \underset{-}{-} \mathrm{-} .0 \mathrm{~g} / \mathrm{L} \mathrm{NaCl}$.

units in a protonated form (-COOH) can form hydrogen bonds (attractive interactions) with one another. When the $\mathrm{pH}$ lower than 4.0 most of group (-COOH) unionized, electrostatic repulsion between negative charges lower and the dehydration of hydrophobic diethyl groups of the copolymers increase, which makes an attractive interaction between them dominant and induces collapse of the chain, so the LCST of copolymers fell. When $\mathrm{pH}$ is between 4.0 and 8.0 the ionization states of MAA units are dependent on $\mathrm{pH}$. As the $\mathrm{pH}$ increasing, the ionized carboxylic acid groups' increase, the number of intra-chain hydrogen bonding decrease and the repulsive interactions extended the copolymer chain, so the LCST of copolymers increase sharply. Whereas when the $\mathrm{pH}$ of copolymers above 8.0 the properties of neutral disappear and ionized forms are in the highest flight, the content of solutions do not change, so the plateau values are obtained. Finally, Figure 7 presents temperature-dependent $\mathrm{pH}$ of $0.20 \mathrm{wt} \%$ copolymer $\left(2^{\#}\right)$ in different salt solutions. It can be seen that the effect of $\mathrm{pH}$ to LCST are similar in different salt solutions.

\section{Conclusions}

In this study, a series of $\mathrm{pH}$ and temperature-responsive DEA-co-MAA random copolymers were synthesized and characterized. The IR and ${ }^{13} \mathrm{C}$ NMR spectra of P(DEA-coMAA) copolymers indicate that successful polymerization of each of the monomers has taken place. The presence of $\mathrm{NaCl}$ significantly decreased the LCST of all copolymers and accelerated their phase transition. And the LCST values were found to increase slightly initially with increasing MAA content; further increase MAA content induced the LCST to decrease. The results indicate that the lower critical solution temperature (LCST) increased with the increase of $\mathrm{pH}$. It is hoped that the solubility properties of the thermo sensitive copolymers can be used as a means of controlling release in orally delivered drug devices.

Further work has to be undertaken in order to synthesize the crosslinked complexes of $\mathrm{P}(\mathrm{DEA}-\mathrm{co}-\mathrm{MAA})$. Also incorporation of a number of different drugs into the gels is to be carried out. By doing so, it is hoped to design drug loaded gels which will release the drug at a predicted rate in given media, depending on the temperature, $\mathrm{pH}$ and salt concentration.

Acknowledgments. This work was supported by the national natural science foundation of China (No.20171019) and natural science foundation of Gansu Province (3ZS041A25-009).

\section{References}

(1) Y. H. Bae, T. Okano, and S. W. Kim, J. Control. Release, 9, 271 (1989).

(2) G. Anna, H. B. You, J. Harvey, F. Jan, and W. K. Sung, Macromolecules, 27, 4167 (1994).

(3) J. Kopecek, J. Vacik, and D. Lim, J. Polym. Sci. Polym. Chem. Ed., 9, 2801 (1971).

(4) H. Park and J. R. Robinson, J. Control. Release, 2, 47 (1985).

(5) S. R Eisenberg and A. J.Grodzinski, J. Membr. Sci., 19, 173 (1984).

(6) I. Kwon, Y. H. Bae, T. Okano, and S. W. Kim, Nature, 354, 291 (1991).

(7) J. Ricka and T. Tanaka, Macromolecules, 17, 2916 (1984).

(8) M. Irie, Adv. Polym. Sci., 110, 49 (1993).

(9) C. S. Brazel and N. A. Peppas, Macromolecules, 28, 8016 (1995).

(10) M. J. Snowden, D. Thomas, and B. Vincent, Analyst, 118, 1367 (1993).

(11) G. H. Chen and A. S. Hoffman, Bioconjugate. Chem., 4, 509 
(1993).

(12) H. Bae, T. Okano, and S. W. Kim, Macromol. Chem. Rapid. Commun., 9, 185 (1988).

(13) A. S. Hoffman, Controlled drug delivery challenges and strategies, Intelligent, polymers, K. Park, Ed., Washington, DC, ACS, 1997, pp 485-498.

(14) N. A. Peppas, Curr. Opin. Colloid Interface Sci., 2, 531 (1997).

(15) X. Y. Wu and P. I. Lee, Pharm. Res., 10, 1544 (1993).

(16) J. Huang and X. Y. Wu, J. Polym. Sci. Polym. Chem., 37, 2667 (1999).

(17) J. Moselhy, X. Y. Wu, R. Nicholov, and K. Kodaria, J. Biomater. Sci. Polym. Ed., 11, 123 (2000).

(18) C. Choi, M. K. Jang, and J. W. Nah, Macromol. Res., 15, 623 (2007).

(19) K. Zhang and X. Y. Wu, Biomaterials, 25, 5281 (2004).

(20) H. D. Han, D. E. Nam, D. H. Seo, T. W. Kim, and B. C. Shin, Macromol. Res., 12, 507 (2004).

(21) L. Sherwood, Human physiology from cells to systems, 3rd ed., Belmont, CA, Wadsworth Publishing Company, 1997, pp 121-165.
(22) G. R. Martin and R. K. Jain, Cancer Res., 54, 5670 (1994).

(23) M. Panayiotou and R. Freitag, Polymer, 46, 6777 (2005).

(24) Z. Ying, K. Juan, and T. Tian, Polymer, 47, 7702 (2006).

(25) J. S. Yoo, M. S. Kim, and D. S. Lee, Macromol. Res., 14, 117 (2006).

(26) I. Idziak, D. Avoce, and D. Lessard, Macromolecules, 32, 1260 (1999).

(27) S. Fujishige, K. Kubota, and I. Ando, J. Phys. Chem., 93, 3311 (1989).

(28) S. B. Lee, S. C. Song, J. I. Jin, and Y. S. Sohn, Macromolecules, 32, 7820 (1999).

(29) X. M. Liu, Y. Y. Yang, and K. W. Leong, J. Colloid Interf. Sci., 266, 295 (2003).

(30) X. M. Liu, K. P. Pallathadka, Y. Y. Yang, S. Y. Chow, and C. He, Biomaterials, 25, 2619 (2004).

(31) F. Garret-Flaudy and R. Freitag, J. Polym. Sci. Polym. Chem., 38, 4218 (2000).

(32) L. H. Gan, W. Cai, and K. C. Tam, Eur. Polym. J., 37, 1773 (2001).

(33) M. S. Jones, Eur. Polym. J., 35, 795 (1999). 